\title{
Synthesis and Spectral Characterization of Verdantiol Schiff base with GC-MS for Synthetic Ingredients in Fragrances Industry
}

\section{CANDRA IRAWAN, DIAN ISLAMIYATI', EVA YULIANA ${ }^{2 *}$, SINGGIH WIBOWO', RIKA PERDANA PUTRI ${ }^{3}$ and IMALIA DWI PUTRI ${ }^{1}$}

\author{
'Departement of Chemical Analysis, Politeknik AKA Bogor, Bogor 16154, Indonesia. \\ ${ }^{2}$ Departement of Food Industry Quality Assurance, Politeknik AKA Bogor, Bogor 16154, Indonesia. \\ ${ }^{3} \mathrm{PT}$. Nilam Widuri Bogor, Indonesia. \\ *Corresponding authors E-mail: evayuliana@gmail.com \\ http://dx.doi.org/10.13005/ojc/350616
}

(Received: November 06, 2019; Accepted: December 06, 2019)

\begin{abstract}
In this study, we have synthesized verdantiol Schiff base using a simple condensation method. The color of product has been compared with the verdantiol standard. There was a little color difference between the product and the standard. In order to confirm the product, gas chromatogram-mass spectrometer (GC-MS) has been used. The existence of verdantiol Schiff base molecule ion $\left(\mathrm{M}^{+}\right)$ was confirmed at $\mathrm{m} / \mathrm{z}=337.2$ because this value was equal to the value of its molecular weight of $337.47 \mathrm{~g} / \mathrm{mol}$. This finding will be important for fragrance industry due to a simple method can be used to produce an important verdantiol Schiff base.
\end{abstract}

Keywords: Verdantiol, Schiff base, GC-MS, Fragrance.

\section{INTRODUCTION}

Personal care products such as soap, toothpaste, cosmetics, shamphoo and perfumes contain fragrances. ${ }^{1}$ Fragrance is a mixture of several chemical compounds which specifically produce aroma compounds. ${ }^{2,3,4,5}$ Fragrance material usually contains synthetic aroma compounds or extracted natural compound which is dissolved in alcohol. ${ }^{6}$ Fragrance quality can be seen from volatility, odor, stability, and color. ${ }^{2,7,8}$

In order to produce high-quality fragrance, a synthetic compound such as Schiff base is added.
Schiff base is a compound obtained from the reaction between aldehydes and primary amines. ${ }^{9,10}$ In this reaction, water is obtained as a byproduct. This condensation reaction is reversible using acid or base catalysts with heating. Vacuum condition is applied to minimize the damage of Schiff base products, water is separated from the products and

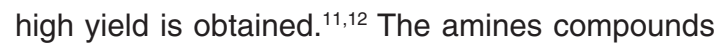
which are usually used in the fragrance industry are methyl anthranilate and ethyl anthranilate. While the commonly used aldehyde compounds are alkyl or aromatic aldehydes such as decanal, benzaldehyde, terpene aldehyde (hydroxycitronellal). ${ }^{9,13}$

This is an Open Access article licensed under a Creative Commons license: Attribution 4.0 International (CC- BY). Published by Oriental Scientific Publishing Company @ 2018

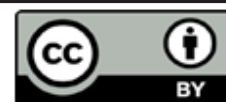


Schiff base obtained from methyl anthranilate is highly needed in fragrance industry. Schiff base is able to increase the chemical and temperature stability from fragrances. ${ }^{14}$ Several schiff bases have been using in fragrance industry such as Jasmea, Cyclantine, Indolen, Vertosine, Agrea, Decimea, Nonimea, Ocmea, Isonomilat 258 E, Amandolen, Canthoxalia, Acaciol, Aurantiol, Lyrame and verdantiol ${ }^{14,15,16}$. Verdantiol is produced by condensation reaction of Lilyall and methyl anthranilate ${ }^{14}$.

Mass spectrometry tandem with gas chromatography (GC/MS) is normally used for direct analysis of components existing in fragrance. In recent years GC-MS studies have been increasingly applied for the analysis of fragrance in the industry. This technique has proved to be a valuable method for the analysis of polar components and (semi) volatile, and only a few grams of sample are required ${ }^{17,18,19}$.

\section{EXPERIMENTAL}

\section{Materials and methods}

Methyl anthranylate, Lilyall (aq) and ethanol $99 \%(\mathrm{v} / \mathrm{v})$ were used as the main materials. The experiment consists of three steps (production, confirmation, and color observation) of verdantiol Schiff base.

\section{Production}

Production of verdantiol Schiff base was carried out by a simple condensation of method at a temperature of $110^{\circ} \mathrm{C}$ for $30 \mathrm{~min}$ using hotplate stirrer. The main composition of verdantiol Schiff base is $9.070 \mathrm{~g}$ methyl anthranilate $(a q)$ and Lilyall (aq) (12.259 g) was added for obtaining verdantiol Schiff base.

\section{Confirmation}

Schiff base products $(0.05 \mathrm{~g})$ were diluted with ethanol $99 \%(\mathrm{v} / \mathrm{v})$ until the weight was $1 \mathrm{gram}$. Then homogenized to produce $5 \%(\mathrm{w} / \mathrm{w})$ solution. This Schiff base solution was analyzed by gas chromatography-mass spectrometry (GC-MS). GC-MS was perfomed by using Agilent $5975 \mathrm{C}$ series MSD, capillary column ( $5 \%$ Phenyl Methyl Siloxane $325^{\circ} \mathrm{C}$, length $=30 \mathrm{~m}$, internal diameter $=320 \mu \mathrm{m}$, film thickness $=0.25 \mu \mathrm{m}$ ), carrier gas was helium, carrier gas pressure was $7.0531 \mathrm{psi}$, injector temperature was $100^{\circ} \mathrm{C}$, injection volume was $0,2 \mu \mathrm{L}$, split injection technique with split ratio $80: 1$, the column temperature was $100^{\circ} \mathrm{C}$ for $5 \mathrm{~min}$, the increment rate was $15^{\circ} \mathrm{C} / \mathrm{min}$, final temperature was $250^{\circ} \mathrm{C}$ for 5 minute. Total running time was 25 minute.

\section{Color Observation}

The color observation was carried out by at least three panelists at the booth. The product solution is poured into a tube that is $1.3 \mathrm{~cm}$ in diameter and $10 \mathrm{~cm}$ high to the specified limit (about $5 \mathrm{~cm}$ ). The product was also documented using a camera. Images are observed in places that have enough light, and there are no reflections of light.

\section{RESULT AND DISCUSSION}

\section{Verdantiol Schiff base Preparation}

The obtained verdantiol Schiff base can be seen in Fig. 1. Fig. 1 shows that the color of verdantiol Schiff base is yellow, the standard color is more concentrated. Verdantiol Schiff base is obtained from Lilyall which has carbonyl group reacting with amine group in methyl anthranilate passing crossed aldol condensation reaction. If an aldehyde/ketone without $\alpha$-hydrogen is mixed with aldehyde has 2 isomers those are $R^{\star}$ and $S^{*}$. The reaction occurs in the production of verdantiol Schiff base is shown below (Figure 2).

\section{Analysis of Schiff base Verdantiol using GC MS}

Analysis of verdantiol Schiff base product using GC MS obtained chromatogram and mass spectrum as seen in Fig. 3 and 4. Mass spectrum displays the number of molecule fragment which is produced from the fraction of chemical component having a different molecular weight. ${ }^{20}$ Analysis of mass spectrum is based on matching percentage value, base peak and the fraction of mass spectrum compared to the spectrum from Wiley. L. literature.

Figure 3 shows verdantiol with molecular formula $\mathrm{C}_{22} \mathrm{H}_{27} \mathrm{NO}_{2}$ (molecular weight $=337.47 \mathrm{~g} / \mathrm{mol}$ ) with more than $90 \%$ similarity. The number of peaks is the reaction results between Lilyall and methyl anthranilate which produce five different shapes of molecules. Theoretically, there are six isomers produced from the reaction between lilyall $\left(R^{*}, S^{*}\right)$ with methyl anthranilate. 


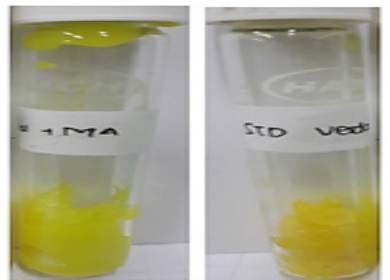

Fig. 1. The obtained verdantiol (a) and verdantiol Schiff base standard (b)
Chromatogram result from verdantiol molecule formation (Fig. 2a) only shows 5 isomers. This might be caused by the structure of methyl 2-((1S,2R)-2-benzyl-1-hydroxypropylamino) benzoate which was not formed due to steric hindrance of a bulky group in a transition state. Bulky structure in the transition state causes activation energy getting very high. ${ }^{21}$<smiles>CC(C)CC(C)C(C)(C)C(C)C</smiles>

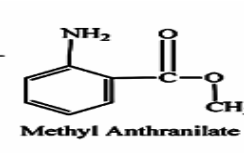<smiles>COC(=O)C1=CCC(NC(C)(C)C)CC1</smiles>

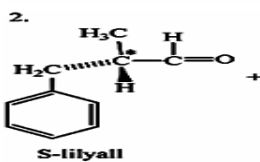

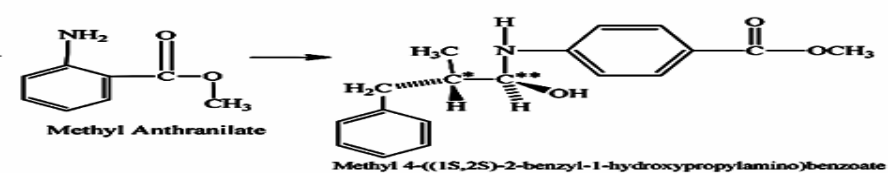<smiles>COCC(C)(C)CC(C)CC1CCCCC1</smiles>

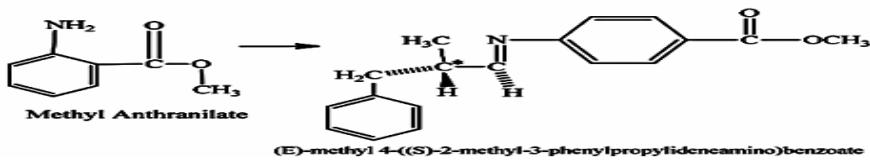

4.

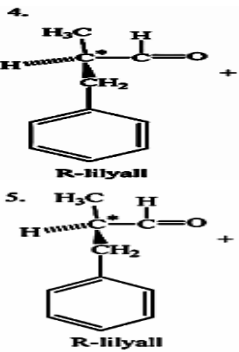

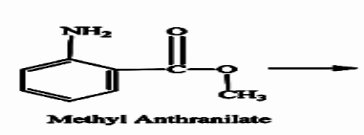

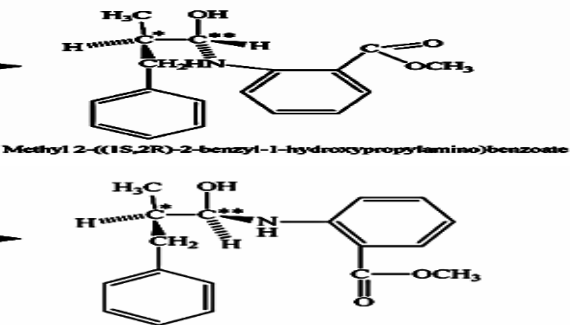

Fig. 2. Schematic diagram of verdantiol schiff base formation

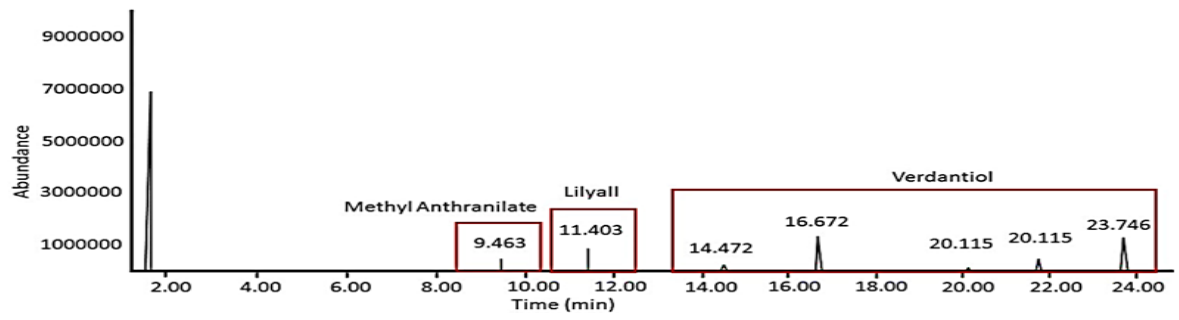

(a)

\begin{tabular}{|c|c|c|c|c|c|c|}
\hline PKK & RT & Area \% & Library/liD & Ref* & CAS\# & Qual \\
\hline 1 & 9.466 & 3.48 & $\begin{array}{l}\text { CISSBL ANTRANILATE } \\
\text { METHYL ANTRA }\end{array}$ & 1360 & oooooo-oo-o & 96 \\
\hline 2 & 11.404 & 6.17 & C:ISBL & 15 & $000080-54-6$ & 99 \\
\hline 3 & 14.473 & 7.79 & C:ISBDANTHOL & 1470 & $000091-51-0$ & 94 \\
\hline 4 & 16.671 & 33.49 & Ciss:LL̃ & 1470 & $000091-51-0$ & 91 \\
\hline 5. & 20.116 & 2.28 & C:ISBAL & 1470 & $000091-51-0$ & 96 \\
\hline 6 & 21.766 & 9.47 & C:ISBAL & 1470 & $000091-51-0$ & 94 \\
\hline 7 & 23.747 & 37.34 & C:NSB-L & 1470 & $000091-51-0$ & 93 \\
\hline
\end{tabular}

(b)

Fig. 3. (a) Verdantiol molecule chromatogram (b) Wiley. L literature for verdantiol molecule 


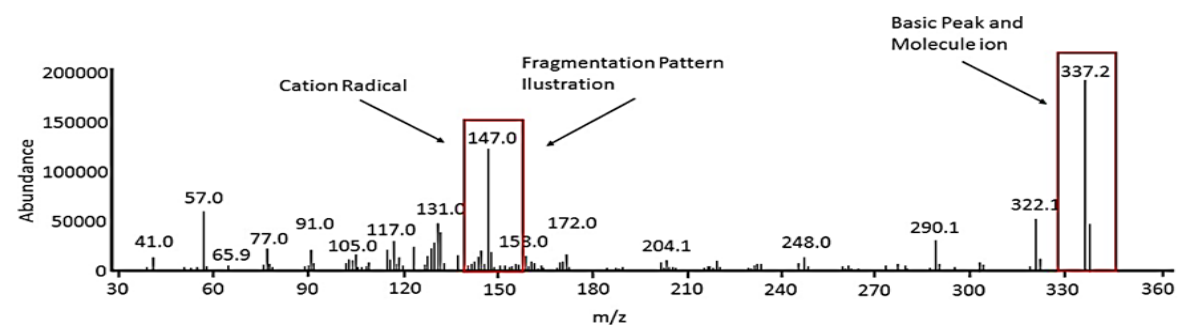

Fig. 4. Mass spectrum of verdantiol molecule

Mass spectrum in Fig. 5 shows peaks having different $\mathrm{m} / \mathrm{z}$ with main peak at $\mathrm{m} / \mathrm{z}$ of 337.2 and 147.0. McLafferty stated that the other peaks with the smallest abundance were smaller ion fraction radical and ion or radical small molecule. ${ }^{22}$ Molecule mass spectrum in Fig. 3 shows that the existence of verdantiol Schiff base molecule ion
$\left(\mathrm{M}^{+}\right)$at $\mathrm{m} / \mathrm{z}=337.2$ because its value was equal to the value of the molecular weight of verdantiol Schiff base which was $337.47 \mathrm{~g} / \mathrm{mol}$. The peak at $\mathrm{m} / \mathrm{z}=147$ was the fragmentation from verdantiol. The following illustration shows the formation of molecule ion, basic peak and cation radical.

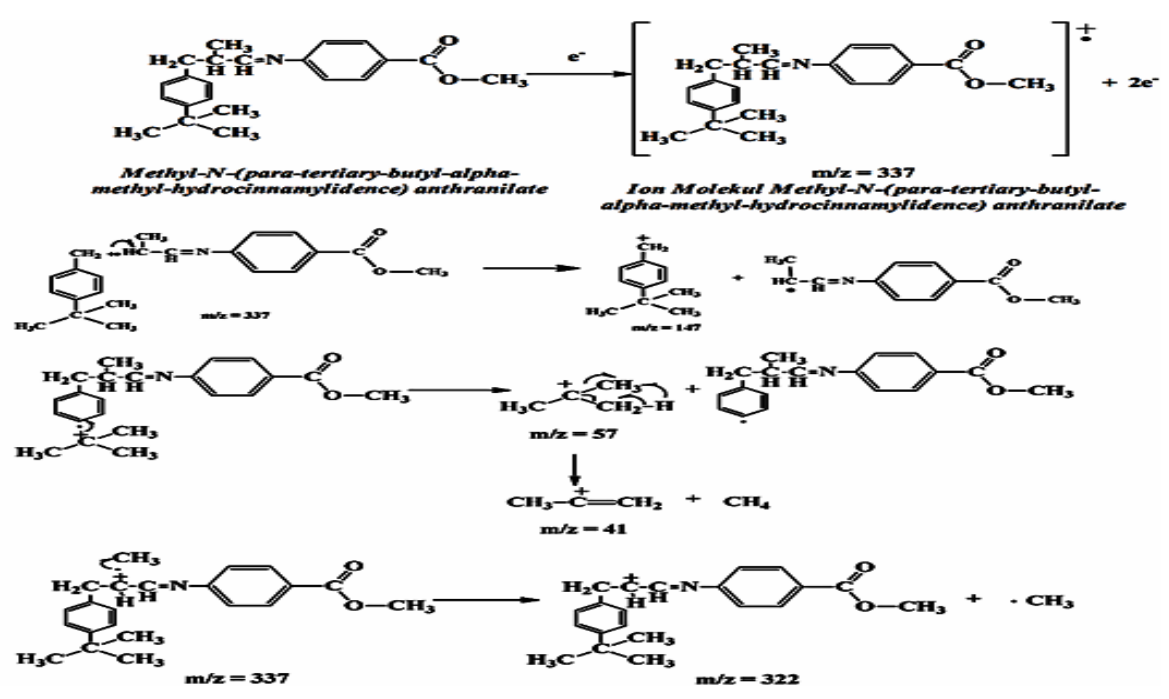

Fig. 5. Fragmentation of verdantiol

CONCLUSION

Verdantiol Schiff base has been successfully synthesized by using a simple condensation method. The color of the product was yellow and almost similar to the standard color. However, the standard color was more concentrated compared to the product. From GC-MS analysis, the peak at $\mathrm{m} / \mathrm{z}=147$ was the fragmentation from verdantiol.
ACKNOWLEDGEMENT

This study was supported by Research Program of Politeknik AKA Bogor.

\section{Conflict of Interests}

The authors declare that there is no conflict of interests regarding the publication of this paper.

\section{References}

1. Villa, C.; Gambaro, R.; Mariani, E.; Dorato, S. Journal of Pharmaceutical and Biomedical Analysis., 2007, 44, 755-762.

2. Herman, S. J. Allured Publishing Corp., England, 2002.

3. Ansari, R.M.; Bhat, B.R. J. Chem. Sci. 2017., 129, 1483-1490.
4. Da Silva, C.M.; da Silva, D.L.; Modolo, L.V.; Alves, R.B.; de Resende, M.A.; Cleide, V.B.; Martins, C.V.B.; de Fatima, A. J. Adv. Research., 2011, 2, 1-8.

5. Nagesh, G.Y.; Mruthyunjayaswamy, B.H.M. J. Molecular Structure., 2015, 1085, 198-206.

6. Rowe, D. Blackwell Publishing Ltd. USA., 2005. 
7. Quellet, C.; Schudel, M.; Ringgenberg, R. Chimia., 2001, 55, 421-428.

8. Gygax, H.; Koch, H. Chimia., 2001, 55, 401405.

9. Calkin, R.R.; Jellinek, J.S. John wiley \& Sons, Inc. Canada., 1994.

10. Dhokale, N.T.; Karale, B.K.; Nagawade, A.V. Orient. J. Chem., 2017, 33(1),165-172.

11. Sarkic, A.; Stappen, I. Cosmetics., 2018, 5 (1), 11.

12. Kumar, A. Departement Pharmacy University of Punjab Technical Jalandhar, India., 2011.

13. Cortez-Pereira, C.S.; Baby, A.R.; Velasco, M.V.R. J. Cosmetic Dermatology., 2010, 9, 230-241.

14. Sell, C.S. RSC Publishing. Dorchester., 2006.

15. Irawan, C.; Indryati, S.; Lestari, E.S.;
Hidaningrum, A.; Supriyono. Orient. J. Chem., 2018, 34(1), 394-400.

16. Irawan, C.; Islamiyati, D.; Putri, R.P.; Madiabu, M.J.; Supriyono. Orient. J. Chem., 2018, 34, 3118-3122.

17. Asten, A.V. TrAC-Trend Anal Chem., 2002, 21(9-10),698-708.

18. Begnaud, F.; Chaintreau, A. Phil. Trans. $R$. Soc. A., 2016, 374, 20150365.

19. Debonneville, C.; Chaintreau, A. J. Chromatogr. A., 2004, 1027, 109-115.

20. Harianingsih, R.; Wulandari, C.; Harliyanto, C.N.; Andiani. Techno., 2017, 18(1), 23-27.

21. Fessenden, R.J.; Fessenden, J.S. W. Grant Press. Boston, USA., 1982.

22. McLafferty, F.W. University science books. California, USA., 1980. 